\title{
Nature and biotechnology
}

\author{
150 years after its founding, Nature has not only published some of biotech's seminal papers, but also profoundly \\ influenced the sector's impact on society.
}

O n 4 November 1869, the first edition of 'A Weekly Illustrated Journal of Science' entitled Nature was published in London. In the first article of that very first issue, Darwin's bulldog, Thomas Henry Huxley, launched into 29 straight paragraphs of Goethe. He began: "Nature! We are surrounded and embraced by her: powerless to separate ourselves from her, and powerless to penetrate beyond her." A century and a half later, Nature's pages have not only disclosed many of its namesake's impenetrable secrets, but also documented their translation into the 'new' discipline of biological engineering. In line with the journal's mission of bringing "news of the latest discoveries and inventions to scientists and the public alike," it has played an important role in shaping the perception of biotech in the public's imagination.

In addition to its physical and social sciences content, Nature has always been a venue for disclosing the techniques that underpin much of modern biology (see Supplementary Table 1). In biotech's earliest years, though, Nature played more of a supporting role than lead. In the 1970s, it was PNAS that published the key papers describing different parts of the recombinant DNA toolkit. In later decades, the techniques that would feed into the human and other genome projects - PCR, yeast artificial chromosomes, phage display, cDNA sequencing and DNA microarrays - found their way into the pages of Science. Increasingly, though, Nature also shared the spoils: in the eighties and early nineties, it published key papers on plant recombinant DNA, antibody display, stem cells, knockout mice, and the prototype automated DNA sequencer that launched Applied Biosystems. In the 2000s, it was a home for synthetic biology, the human genome project's work and the genomics efforts that sprung from it.

Surveying the publication history over the past four decades (see Supplementary Table 1), the time to transition from research discovery to marketed biotech product has, if anything, lengthened. There were 10 years between the paper describing recombinant DNA (1972) and the approval of Humulin
(1982); there was a decade between the first monoclonal antibody (1975) and the first monoclonal product, OKT-3 (1985); and aptamers reached the market (2004) only 14 or so years after their evolution (1991). But gene therapy has taken nearly a quarter of a century and CAR-T cells nearly 30 years. It remains to be seen whether editing technologies, such as TALENs, CRISPRCas9, ADAR and now Prime, will buck the trend.

Techniques, rather than products, have not followed the same trend. A Correspondence published in this issue suggests that, as the decades have passed, the time between the first description of a research technique and its commercialization or commoditization has been shrinking. Thus, biotech techniques of the 1970s and 1980s, with the exception of PCR, took 14-25 years to reach the feefor-service stage; those of the 1990s and 2000s took 5-7 years; and those of the past decade have taken just two years. Overall, biotechnologies have been democratizing - getting into the hands of non-experts and the public - earlier and earlier over time.

But Nature's contribution goes far beyond simply publishing papers. True to its mission, several times in its history, the journal has actively shaped the public's perception of biotech, which has had profound consequences for the sector and its products.

In 1997, following the birth of Dolly the sheep, a paper describing live offspring after nuclear transfer from adult cells ignited a media firestorm. Despite assurances that human reproductive cloning was unsafe and unacceptable, public fears rose around the impending likelihood of human cloning. A Wellcome report attributed the intense controversy to "a strong narrative already established by popular cultural imagery in science fiction." Dystopian visions continue to shadow human applications of bioengineering and emphasize the need for continued engagement on ethical and social implications.

Just three years later, a short paper on the toxicity of Bacillus thuringiensis toxins to monarch butterfly larvae trapped in a sandwich box was seized upon by environmentalists as validating recombinant DNA as a threat to ecosystems, a message that permeated into the public consciousness in Europe and beyond. Although a set of 2001 papers in PNAS established that the threat was small, the subsequent mobilization of public and political sentiment against transgenic products meant that GM crops never really recovered. Environmentalist concerns about biotech crops continued to hit headlines when a Nature paper - subsequently subject to an editorial expression of concern - claimed gene flow from transgenic corn into wild relatives in Mexico and their progeny.

But clearly the most far-reaching Nature publications for biotech have been those around the human genome, with the landmark description of the sequence in 2001. These papers led to a multidisciplinary and collaborative biology that has begun to bring genomics into people's lives and translate into precision medicines. With high-throughput, multiparallel analytical technology, sequencing and powerful computational approaches, -omic research is finally allowing us to learn the secrets - as Huxley put it, "the wonder and the mystery" - of ourselves and the world around us.

None of this would be possible without our ability to gather and share data. Here, too, Nature deserves plaudits. In 2001, faced with pushback from commercial interests and biotech company Celera Genomics, the journal staunchly defended the need for transparent and public release of sequence data associated with publication of the human genome. This foundational principle remains as important today as ever. It is not just good for science. It is the foundation on which the biotech industry has been built.

Published online: 3 December 2019 https://doi.org/10.1038/s41587-019-0362-1

Additional information

Supplementary information is available for this paper at https://doi.org/10.1038/s41587-019-0362-1. 